\title{
Expediting the Irksome - the Cortical Approach: A Case report
}

\author{
Dr. Pujan Acharya, ${ }^{1}$ Dr. Charanjeet Singh Saimbi, ${ }^{2}$ Dr. Khushbu Adhikari, ${ }^{3}$ \\ Dr. Bikash Kumar, ${ }^{4}$ Dr. Sita Niure ${ }^{5}$ \\ ${ }^{1,5}$ Resident, ${ }^{2}$ Professor, ${ }^{3,4}$ Assistant Professor, Department of Periodontology and Oral Implantology, \\ Universal College of Medical Sciences, Bhairahawa, Nepal
}

\begin{abstract}
Corticotomy assisted orthodontic treatment is a promising interdisciplinary approach, which has offered solution to many limitations in the orthodontic therapy. The procedure involves the alveolar decortication in the form of cortical grooves and perforations performed around the teeth that are to be moved. In this case report, a 17 year old male under fixed orthodontic therapy with a complaint of delayed protraction of mandibular second molars underwent corticotomy procedure. The decortication was done followed by elevation of buccal and lingual flaps. After 2 weeks of the surgical procedure, orthodontic tooth movement was initiated.
\end{abstract}

Key Words: Corticotomy, orthodontic tooth movement, regional acceleratory phenomenon

\section{INTRODUCTION}

Interdisciplinary orthodontic tooth movement has resolved the apprehension related to prolonged treatment duration amongst the adolescent and adult patients. Various methods have been introduced and documented to accelerate such movement. Corticotomy-assisted orthodontic tooth movement has become one of the most promising technique which has reduced the treatment time compared to conventional orthodontic therapy by almost about $1 / 3-1 / 4$ time. ${ }^{1-3}$

This technique was first described by Bryan in 1892 and Cunningham in $1893 .{ }^{4}$ Later in 1959, Kole introduced a surgical procedure involving both osteotomy as well as corticotomy to expedite the movement ${ }^{5}$ and called it "en bloc" tooth movement. ${ }^{6}$ However, Kole's technique posed considerable risk to the periodontium and tooth vitality.

This led to the introduction of a newer technique called Accelerated Osteogenic Orthodontics or Periodontally Accelerated Osteogenic Orthodontics ${ }^{7}$ in 2001 by Dr. Thomas Wilcko (Periodontist) and Dr. William Wilcko (Orthodontist)

\section{Correspondence:}

Dr. Pujan Acharya

Department of Periodontology \& Oral Implantology, Universal College of Medical Sciences, Bhairahawa, Nepal email:poojan_drn@yahoo.com

\section{Citation}

Acharya P, Saimbi CS, Adhikari K, Kumar B, Niure S. Expediting the irksome - the cortical approach: a case report. J Nep Soc Perio Oral Implantol. 2017;1:34-6. which was later on patented as Wilckodontics. The biologic rationale behind tooth movement following corticotomy facilitated orthodontics was explained as a result of demineralization/ remineralization process occurring in and around the corticotomied sites. This was found to be consistent with the "regional acceleratory phenomenon" described by an orthopedist, Harold Frost. ${ }^{8}$ In the present case report, a modified technique of conventional corticotomy has been implemented which is based on this principle and eliminates the need of bone graft.

\section{CASE REPORT}

A 17 year old, systemically healthy male patient undergoing orthodontic therapy for nineteen months was referred from the Department of Orthodontics with delayed protraction of mandibular right second molar.

The intra-oral examination revealed missing mandibular right and left first molars with history of extraction before orthodontic treatment due to gross caries. A mini-implant

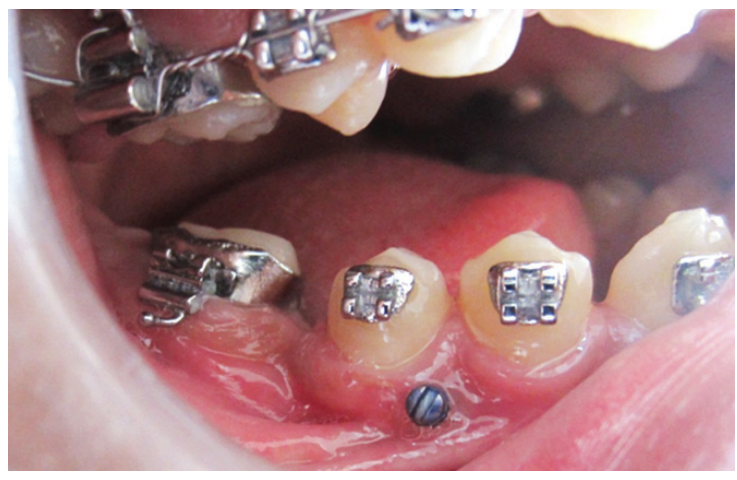

Figure 1: Pre-operative View 


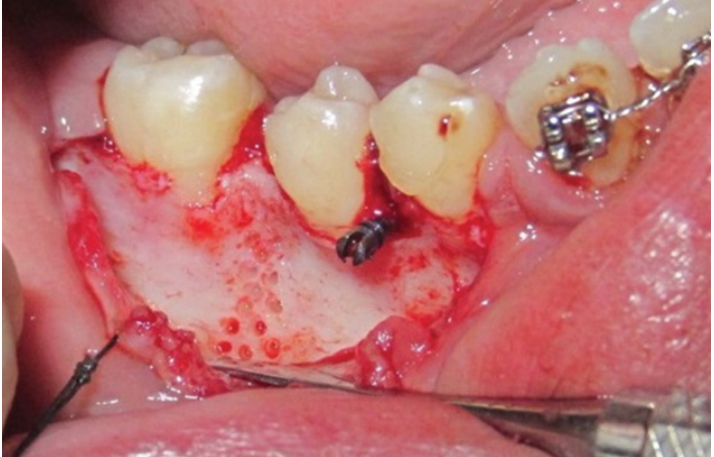

Figure 2: Cortical perforations made

for protraction of the second molar had been placed between lower premolars bilaterally (Figure 1). The periodontal condition was normal with probing pocket depth in relation to buccal and lingual surfaces of molars and premolars calibrated to be $2 \mathrm{~mm}$ each. The mesio-distal width in the edentulous space was measured to be $4 \mathrm{~mm}$ without any radiographic abnormality.

A corticotomy procedure was planned to expedite the tooth movement with the consent of the patient.

Corticotomy was performed one month after oral prophylaxis. Crestal incision inclined slightly towards the lingual aspect was placed, followed by two releasing incisions: one along the mesial line angle of the first premolar and the other along the distal line angle of the second molar tooth under local anaesthesia (right inferior alveolar nerve block along with lingual and long buccal nerve block) with a BP blade no. 15. Mesially, the flap was overextended so as to surpass the area where mini-implant was placed. Crevicular incision around each tooth was placed with BP blade No. 12 and a full thickness flap was raised on both buccal and lingual sides.

Around 12-14 perforations were made on both buccal and lingual edentulous areas (Figure 2). A $2 \mathrm{~mm}$ round, carbide bur under continuous, copious irrigation with cooled normal saline was used during decortication, starting $2 \mathrm{~mm}$ below the level of the alveolar crest.

Bleeding from the corticotomied sites suggested the perforation reaching medullary bone. A depth of 1-2 mm was confirmed with a periodontal probe. Care was taken not to damage any neurovascular structures. The area was well irrigated and the flap was sutured back by interrupted suture using a 3-0 non-resorbable silk suture (Figure 3). Periodontal dressing was placed for the comfort of patient. Post-surgical instructions were given and analgesic, antibiotics and antiseptic mouthwash were prescribed.

In a week time, uneventful healing was observed, the sutures were removed and oral hygiene reinforcement done. Active orthodontic treatment was initiated two weeks after the procedure.

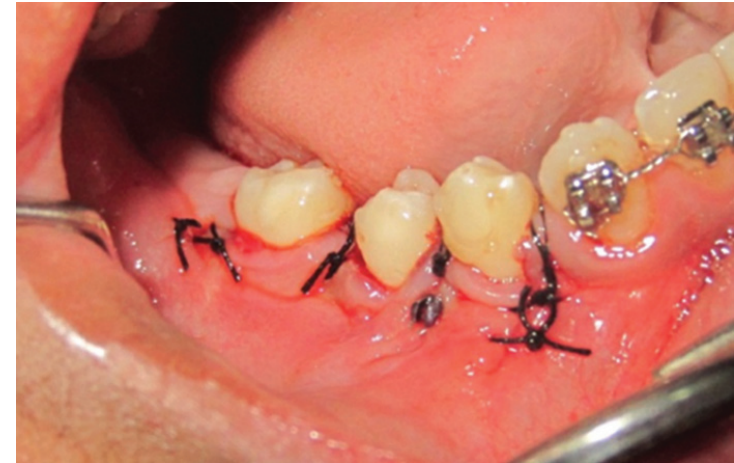

Figure 3: Sutures placed

\section{DISCUSSION}

Decortication ensues a phase of osteopenia which exhibits a temporary reduction in the mineral content of the bone. As a result, the tissues of alveolar bone release rich deposits of calcium and mineralization of thus formed new bone occurs in 2-3 months time. ${ }^{9}$ Hence the advantage is gained by initiating orthodontic tooth movement within this time frame. According to the regional acceleratory phenomenon, there is a direct correlation between the degree of injuring a bone and intensity of its healing response. Suya in 1991 recommended that after corticotomy, orthodontic treatments should be completed in the first three to four months, before fusion of the tooth-bone units.

The procedure has several advantages which include shorter treatment duration as a case reported by Wilcko where crowding of an adult female was treated in four and half months. ${ }^{10}$ Besides, less likelihood of root resorption, limited history of relapse and the post-operative periodontal stability has increased the demand and acceptance of this approach. Similarly, in the present case, post-operative evaluation after 1 month revealed good preservation of interdental papillae, no probing pocket depths greater than $2 \mathrm{~mm}$, and no undesirable gingival changes, consequently contributing to periodontal stability. Most important of all, the desired space closure was achieved in 2 months duration (Figure 4). However, it has few contraindications such as active

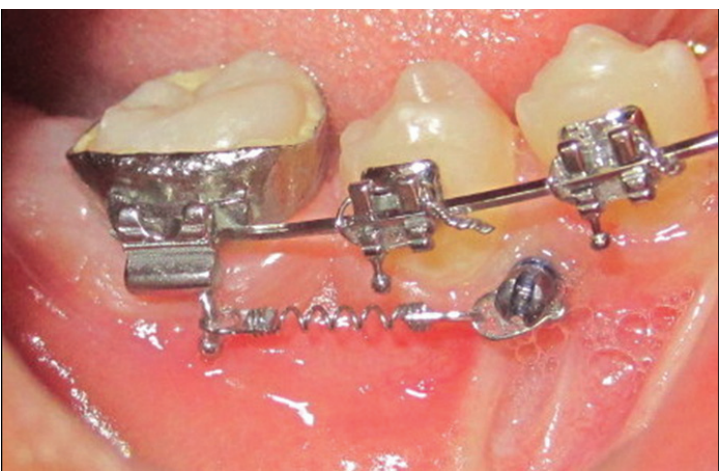

Figure 4: Space closure after 2 months 
periodontal disease, inadequate width of attached gingiva and patients who take nonsteroidal anti-inflammatory drug on a regular basis. Moreover, class III malocclusion cases are also dissuaded from this treatment protocol. ${ }^{9}$

The invasive nature of the surgical approach demanded a nonaggressive and patient compliant procedure leading to the advent of alternative approach like peizocision introduced by Dibart et al. in 2009. It has gained popularity in inducing surgical insult to bone without any flap surgery. In addition, other current methods like micro-osteoperforations, lasers and vibrations have shown to reduce rate of relapse, orthodontic pain and root resorption as well.

The corticotomy procedure has proved to be effective and reliable in conditions where traditional orthodontic therapies fail to produce tooth movement within considerable time period. In the present case, the modified conventional corticotomy technique has been implemented with effective result. Despite studies showing potential of this technique in improving orthodontic outcomes, the quality of evidence available at present, however, is low. Thus, more longitudinal studies are required before it can become a routine procedure for orthodontic tooth movement.

\section{ACKNOWLEDGEMENT}

I wish to thank Dr. Prabhat Ranjan Pokharel, Dept. of Orthodontics and Dentofacial Orthopaedics, BPKIHS, Dharan for his constant motivation and support in carrying out the study.

\section{REFERENCES}

1. Wilcko WM, Ferguson DJ, Bouquot JE, et al. Rapid orthodontic decrowding with alveolar augmentation: Case report. World J Orthodont. 2003;4:197-505.

2. Ferguson DJ, Wilcko WM, Wilcko MT. Selective alveolar decortication for rapid surgical-orthodontic resolution of skeletal malocclusion treatment. In:Bell WE, Guerrero C (Eds): Distraction osteogenesis of the skeleton. Hamilton, BC Decker 2006;199-203.

3. Wilcko MT, Wilcko WM, Marquez MG, et al. The contributions of periodontics to orthodontic therapy. In: Dibart S (Ed): Practical advanced periodontal surgery. Ames,Los Angeles: Wiley Blackwell 2007;23-50.

4. Merrill RG, Pedersen GW. Interdental osteotomy for immediate repositioning of dental-osseous elements. J Oral Surg. 1976;34(2):11825.

5. Köle H. Surgical operations on the alveolar ridge to correct occlusal abnormalities. Oral Surg Oral Med Oral Path. 1959;12(5):515-29.

6. Gantes B, Rathbun E, Anholm M. Effects on the periodontium following corticotomy facilitated orthodontics: case reports. J Periodontol. 1990;61:234-8.

7. Wilcko WM, Wilcko T, Bouquot JE, Ferguson DJ. Rapid orthodontics with alveolar reshaping: two case reports of decrowding. Int J Periodontics Restorative Dent. 2001;21(1):9-19.

8. Yaffe A, Fine N, Binderman I. Regional accelerated phenomenon in the mandible following mucoperiosteal flap surgery. J Periodontol. 1994;65:79-83.

9. Pathak TS, Kini V, Kanagotagi S, Balasubramanian K, Gupta H. Wilckodontics. J Contemp Dent. 2013;3(1):15-9.

10. Wilcko MT, Wilcko WM, Nabil F. Bissada An evidence-based analysis of periodontally accelerated orthodontic and osteogenic techniques: a synthesis of scientific perspectives. Semin Orthod. 2008;14:305-16. 